\title{
CICLOS, TEMPOS E ESPAÇOS EDUCATIVOS NA PROPOSTA PEDAGÓGICA DAS ESCOLAS ITINERANTES DO MST
}

\author{
CYCLES, TIMES, AND EDUCATIONAL SPACES IN A PEDAGOGICAL PROPOSAL OF THE MST'S (LANDLESS WORKER'S MOVEMENT) ITINERANT \\ SCHOOLS
}

CICLOS, TIEMPOS Y ESPACIOS EDUCATIVOS EN LA PROPUESTA PEDAGÓGICA DE LAS ESCUELAS ITINERANTES DEL MST (MOVIMIENTO DE LOS TRABAJADORES RURALES SIN TIERRA)

\author{
MARIANO, Alessandro Santos 1 \\ GEHRKE, Marcos 2 (iD
}

\begin{abstract}
RESUMO
O objetivo deste artigo é analisar a Proposta Pedagógica das Escolas Itinerantes do Paraná, escolas públicas de Educação Infantil, Educação Fundamental e Médio, que funcionam em acampamento de famílias sem terra. Essas escolas são gestadas e orientadas pelo Movimento dos Trabalhadores Rurais Sem Terra (MST) que tem uma proposta educativa que intenciona a formação integral do ser humano, se fundamenta na educação popular, na pedagogia socialista e na pedagogia do movimento. Enquanto procedimento metodológico, utiliza-se o estudo de caso, pesquisa de campo e documental, pelo qual evidencia a práxis de outra forma escolar em articulação com a vida, trabalho e auto-organização dos estudantes.
\end{abstract}

Palavras-chave: Escola Itinerante. Ciclos de Formação. Tempos Educativos.

\section{ABSTRACT}

The objective of this article is to analyze the Pedagogical Proposal of the Itinerant Schools in the State of Parana - Brazil, public elementary and middle schools, which operate in Landless family's camps, managed by the educational project of the Landless Workers Movement (MST), which has an educational focus on the human being integral development, based on popular education, on socialist and on the movement pedagogy. As a methodological procedure, it was used case study, field and documentary research, through that, it was evident the praxis of another way to education connecting life, work and selforganization.

Keywords: Itinerant School. Development Cycles. Educational Stages.

\section{RESUMEN}

El objetivo de este artículo es analizar la Propuesta Pedagógica de las Escuelas itinerantes de Paraná, escuelas públicas de Educación Infantil, Educación Fundamental y Medio, que funcionan en acampamento de familias sin tierra. Esas escuelas son administradas y orientadas por el Movimiento de los Trabajadores Rurales Sin Tierra (MST) que tienen una propuesta educativa que tiene como intención la formación integral del ser humano se fundamenta en la educación popular, en la pedagogía socialista y en la pedagogía del movimiento. Sobre el procedimiento metodológico, se utiliza el estudio de caso, investigación de campo y documental, por el cual se evidencia la praxis de otra forma de educación relacionada a la vida, trabajo, y auto organización de los estudiantes.

Palabras clave: Escuela Itinerante. Ciclos de Formación. Tiempos Educativos.

\footnotetext{
1 Universidade Estadual de Campinas - Unicamp - Campinas - São Paulo - Brasil.

2 Universidade Estadual do Centro-Oeste - Unicentro - Guarapuava - Paraná - Brasil.
} 


\section{INTRODUÇÃO}

O presente artigo apresenta e analisa a proposta pedagógica das Escolas Itinerantes do Movimento dos Trabalhadores Rurais Sem Terra - MST, resultado da pesquisa de mestrado em educação do Programa de Pós-Graduação em Educação da Universidade Estadual do Centro Oeste do Paraná - UNICENTRO, desenvolvida no período entre 2014 e 2016, que consistiu em investigar, por meio da análise documental e pesquisa de campo, o percurso da construção, bem como os fundamentos e características da proposta pedagógica das Escolas Itinerantes organizadas em Ciclos de Formação Humana.

A Escola Itinerante emergiu da luta pelo direito à educação dentro dos acampamentos e assentamentos do MST, deriva da negação do direito à escola para as crianças que estavam nessas comunidades, mas também da necessidade de uma escola que pudesse acompanhar as famílias Sem Terra nos diversos espaços de luta, como as ocupações e marchas, ou seja, uma escola comprometida com a luta por Reforma Agrária, com a construção de outra forma societária, com igualdade e justiça social (MARIANO, 2016).

Esta escola tem origem nas primeiras experiências de escolas dos acampamentos, que existem nesses espaços de luta pela terra em todo o Brasil. Duas experiências importantes estão na origem dessa escola no MST, os acampamentos da Encruzilhada Natalino, em 1978 e a Fazenda Anonni, em 1979, ambos localizados no Rio Grande do Sul, os quais foram fundamentais para constituição do próprio MST. Esses dois acampamentos decidiram organizar uma Escola, em função da preocupação com as mais de 600 crianças sem acesso à educação nesses espaços, pois o poder público não garantia o direito à escola a quem estava em situação de acampamento e quando isso ocorria, em geral levavam as crianças dos acampamentos para as escolas na sede dos municípios. (CAMINI, 2009)

As Escolas Itinerantes têm uma caraterística basilar no processo de elaboração e implementação do seu projeto político-pedagógico, por ser forjada na luta pela terra, se fez num processo coletivo, envolvendo todos os(as) educadores(as), comunidade acampada, o Setor de Educação do MST e a Secretaria de Estado da Educação do Paraná, ora como convidada, ora como instituição pressionada a acatar a proposta educativa. Por isso, se fez um projeto pedagógico em movimento, preocupado com a escolarização e a formação das crianças, adolescentes e jovens que integram a luta pela terra.

Em síntese, evidenciamos que o projeto educativo do MST, desde as sistematizações dos seus cadernos de educação, busca a formação e desenvolvimento pleno do ser humano, das diversas capacidades, o desenvolvimento omnilateral e propõe uma nova forma escolar, que tem como base a pedagogia socialista (PISTRAK, 2009) a pedagogia do oprimido (FREIRE, 1982) e a pedagogia do MST (CALDART, 2004), que enfatiza quatro aspectos: a) uma estrutura organizativa que envolva todos no processo de decisão, com gestão democrática, auto-organização dos estudantes, coletivos pedagógicos, direção coletiva e divisão de tarefas; b) a organização de ambiente educativo, entende que a escola toda educa, dessa forma propõe a organização de tempos educativos como aula, trabalho, oficina, esporte/lazer, estudo, reuniões. E a organização de espaços educativos: horta, jardim, 
oficinas, laboratórios, sala de leitura, espaços de convivências coletivos, dentre outros; c) o trabalho como princípio educativo, que na escola, pode ocorrer nos chamados autosserviços ${ }^{3}$, mas também fora da escola, realizando em conjunto com a comunidade, que chama de trabalho socialmente necessário, objetivando a formação pelo e para o trabalho; d) formas de estudo que materializem uma concepção de conhecimento que permita compreender a realidade (natural e social), nas suas relações e contradições essenciais (MST, 2005).

No processo de criação das Escolas Itinerantes do Paraná, tendo por referência a experiência do Rio Grande do Sul, buscou-se a organização escolar com tempos e espaços educativos, com a auto-organização dos estudantes e um vínculo direto com a luta por Reforma Agrária. As referências foram os princípios pedagógicos da educação do MST, especialmente a relação teoria e prática, educação pelo e para o trabalho, auto-organização dos estudantes, gestão democrática, criação de coletivos pedagógicos.

De 2003 a 2018, num percurso de 15 anos de funcionamento, foram criadas 22 escolas, estimando o atendimento a pelo menos 20 mil estudantes na Educação Infantil, Ensino Fundamental e Médio, de acordo com dados do Setor de Educação do MST/PR.

As Escolas Itinerantes ofertam a educação básica em acampamentos de famílias Sem Terra do Estado do Paraná com uma proposta pedagógica organizada em Ciclos de Formação Humana. Por ser vinculada à rede estadual de ensino, seus(suas) professores(as) são contratados(as) mediante contrato temporário, para a Educação Infantil (4 e 5 anos) e anos Iniciais da Educação Fundamental (6 a 10 anos), são professores unidocentes formados no curso normal de nível médio (magistério) ou pedagogia. E para os anos finais da Educação Fundamental (11 a 14 anos) e Ensino Médio (15 a 17 anos), os(as) professores(as), são licenciados nas diversas disciplinas existentes na grade curricular.

Os resultados dessa pesquisa, que aqui compartilhamos, estão organizados em três partes. $\mathrm{Na}$ primeira, resgatamos a trajetória histórica das Escolas Itinerantes no Paraná, refletindo sobre como foram forjadas na luta pela terra; em seguida nos detemos na Proposta Pedagógica e sua organização em Ciclos de Formação Humana, compreendendo os fundamentos e a forma escolar. E por fim, refletimos sobre os tempos educativos e gestão democrática.

\section{A PROPOSTA POLÍTICO-PEDAGÓGICA E A ORGANIZAÇÃO EM CICLOS DE FORMAÇÃO HUMANA}

Em 2003, a Escola Itinerante no Paraná foi criada com seu Projeto político-pedagógico, abrangendo desde a Educação Infantil, o Ensino Fundamental, o Ensino Médio, Profissionalizante e a Educação de Jovens e Adultos, aprovado pelo Conselho Estadual de Educação do Paraná para quatro anos de experiência, que depois foi renovado para mais outros quatro e assim por diante.

O Projeto político-pedagógico da Escola Itinerante tomou como referência o projeto educativo do MST e foi elaborado em conjunto com o Setor de Educação do MSTIPR, Direção da Escola Base, o

\footnotetext{
${ }^{3}$ Serviços necessários para própria sobrevivência como preparo de alimentos, limpeza entre outros.
} 
Colégio Estadual Iraci Salete Strozak ${ }^{4}$ e a CEC-Coordenação da Educação do Campo ${ }^{5}$ como consta na introdução do documento, (SEED, 2003, p.3):

\begin{abstract}
O presente documento se baseia na experiência de Educação do Movimento Sem Terra em nível nacional, e em específico da experiência da Escola Itinerante no RS, sistematizada ao longo do processo e relatadas em dois cadernos do MST, da Coleção Fazendo Escola. A partir disso, foi organizada a concepção de educação de Escola Itinerante, que está sendo assumida pela SEED-PR e MST.
\end{abstract}

Na perspectiva de construção da Escola Itinerante, buscou-se assumir uma identidade com a luta dos Sem Terra, inclusive imprimindo nos objetivos elementos do projeto educativo do MST, a saber (SEED, 2003, p.9):

1. Garantir o direito à educação de qualidade às crianças, adolescentes, jovens e adultos das comunidades acampadas, através de uma metodologia diferenciada, correspondente à Educação Infantil, Ensino Fundamental, Médio, Profissionalizante e Educação de Jovens e Adultos.

2. Articular ações conjuntas com os órgãos e instituições envolvidas com as questões educacionais dos acampamentos, através da Coordenação de Educação do Campo da Secretaria de Educação do PR e do MST.

3. Proporcionar ao educando oportunidades para construir-se como ser humano, capaz de compreender e interpretar o processo histórico, analisando, comparando, interpretando e transformando a realidade.

4. Fazer a formação em processo dos educadores e educadoras em nível de Magistério articulada à prática pedagógica da Escola Itinerante.

5. Possibilitar aos educandos(as) e educadores(as) da Escola a compreensão da cultura, da identidade e da realidade do campo, partindo dos saberes de "experiência feito" buscando a relação com os conhecimentos universais.

5. Despertar a consciência organizativa e espírito de liderança dos(as) educandos(as), educadores(as) e comunidade acampada.

Quatro objetivos são direcionados para as Escolas Itinerantes: a garantia do direito à educação às crianças; acesso ao conhecimento sistematizado; formação dos educadores e educadoras; formação da consciência crítica e do espírito de liderança. Esses objetivos foram os que orientaram a organização do trabalho pedagógico nas Escolas Itinerantes. O Projeto, inicialmente já apontava como forma de organização os tempos educativos, conforme consta no referido PPP, "ao tempo/aula se articula ao aprendizado dos demais tempos educativos, tais como: tempo leitura, trabalho prático, oficinas (violão, artesanato, horta), cultura, mística, lazer, recreio, auto-organização dos estudantes e outros que podem estar sendo incluídos no decorrer do processo" (SEED, 2003, p.19).

Num primeiro momento, a proposta assumiu a organização em séries. A partir de 2006, as escolas, intensificaram um processo de estudo das experiências dos Ciclos e optaram por reelaborar o Projeto político-pedagógico, chegando à formulação da proposta dos Ciclos de Formação Humana

\footnotetext{
${ }^{4}$ Escola Base da Escola ItInerante no Paraná.

${ }^{5}$ Foi criada em 2003, na Secretaria de Estado da Educação do Paraná, com a função de formular, acompanhar e coordenar ações e políticas públicas de educação para as populações do campo.
} 
(SEED, 2009), pois desde os três primeiros anos de funcionamento da Escola Itinerante, os elementos de ensino como o tema gerador, gestão participativa dos(as) estudantes e educadores(as), se mostravam potenciais, havendo a problemática da organização seriada e a necessidade de aperfeiçoar a avaliação.

Segundo Bahniuk (2015), o processo de estudo e a construção da proposta dos Ciclos de Formação Humana começaram a ser realizados na Escola Base e nas Escolas Itinerantes, a partir de 2005, e, em 2006, o Colégio Estadual do Campo Iraci Salete Strozak protocolou no Núcleo Regional de Educação de Laranjeiras do Sul, o pedido de implementação dos Ciclos de Formação Humana na escola. Nos anos seguintes, diversos elementos da referida proposta foram sendo exercitados nas escolas, mesmo sem aprovação da SEED e do CEE.

O processo de implementação de aspectos do projeto político-pedagógico em Ciclos foi intensificado em 2007. Segundo Oliveira (2014, p. 72), no referido ano, deu-se início à implantação de uma nova forma de organização que exigia romper com a lógica da seriação, da avaliação por nota, como também a lógica da submissão, incorporando práticas reais de auto-organização dos(as) educandos(as). A esse respeito, Freitas (2003, p.57) afirma que "os Ciclos procuram contrariar a lógica da escola seriada e sua avaliação".

Um dos aspectos do Projeto político-pedagógico (SEED, 2009), foi a alteração dos espaços, tempos e os processos avaliativos nas escolas, com a intenção de garantir a aprendizagem dos(as) educandos(as) em sua diversidade, confrontando a linearidade presente na seriação, passando a escola a criar estratégias para contribuir na aprendizagem, excluindo a possibilidade da reprovação. Segundo Krug (2002, p.17), os Ciclos de Formação constituíam uma nova concepção de escola para o Ensino Fundamental, na medida em que adota a aprendizagem como direito da cidadania, propondo o agrupamento dos estudantes, espaço em que as crianças e adolescentes são reunidos pelas suas fases de formação: infância (6 a 8 anos); pré-adolescência (9 a 11 anos); e adolescência (12 a 14 anos).

A proposta em Ciclos avançou para o agrupamento e reagrupamento, conforme idades e fases de vida, com uma forma de avaliação processual e diagnóstica, com pareceres descritivos, com classe intermediária entre cada ciclo para que os estudantes que não tivessem conseguido aprender, pudessem ter um espaço destinado a suprir essa necessidade.

A aprovação do projeto político-pedagógico em Ciclos de Formação Humana pelo Conselho Estadual de Educação se concretizou apenas em 2010, sob o parecer $n^{\circ} 117 / 10$ e a Resolução $n^{\circ}$ 3922/10. De acordo com Bahniuk (2015), essa aprovação aconteceu após a insistência do Setor de Educação do MST junto à SEED e ao Conselho Estadual de Educação do Paraná. Os principais questionamentos da época, por parte da Secretaria de Estado da Educação, relacionavam-se ao fato de incluir as alterações provocadas pela adoção dos Ciclos no sistema da rede estadual de ensino (mesmo questionamento quando se pretendia organizar por etapas, em 2004). De forma mais enfática, os questionamentos estavam em torno do registro da aprendizagem por parecer e não por nota e, também, na ampliação de horas aulas na escola (para suprir a demanda das classes intermediárias).

Para a organização em Ciclos, buscou-se uma compreensão teórica coerente com o projeto de educação do MST, que se fundamenta na concepção do desenvolvimento e aprendizagem de 
Vygotsky (1988), para o qual o desenvolvimento e aprendizagem são reconhecidos como processos distintos, interdependentes e que ocorrem concomitantemente. Assim, ao mesmo tempo em que aprendemos, desenvolvemo-nos e aprendemos mais. Esse novo entendimento possibilitou avançar na relação educador e educando, pois essa concepção entende que o educando não nasce pronto, que ele se desenvolve e aprende sempre. (SEED, 2009)

Além disso, essa base teórica possibilitou que o projeto político-pedagógico estreitasse conexões com a luta do MST e a vida no acampamento, ou seja, para fora da escola, valorizando os aprendizados dos(as) educandos(as), pois compreende-se que os sujeitos não começam a aprender e se desenvolver na escola. Quando ele chega nela, já aprendeu várias coisas e já se desenvolveu parcialmente. O papel da escola é valorizar o processo que já se realizou e contribuir para ampliar a aprendizagem e o desenvolvimento.

Vygotsky (1988) considera ser o melhor aprendizado aquele que se antecipa ao desenvolvimento, ou seja, um aprendizado exigente põe em movimento vários processos de desenvolvimento. Ao elevar o grau de exigência, dentro é claro, das possibilidades do(a) educando(a), a escola e o(a) educador(a) contribuirão mais para o seu desenvolvimento. (SEED, 2009)

Isso acontece porque, segundo Vygotsky (1988), há coisas que o ser humano já consegue fazer sozinho e há coisas que ainda precisa de ajuda para fazer. As coisas que faz sozinho representam o nível de desenvolvimento real e as outras representam o nível de desenvolvimento potencial. O(a) educador(a) realiza, nesta perspectiva, o papel de mediador(a), ou seja, estabelece mediações significativas para que o nível de desenvolvimento potencial se realize. Com a mediação do(a) educador(a), aquilo que o(a) educando(a) precisa de ajuda para realizar hoje pode passar a realizar sozinho amanhã. Para concretizar tais mediações o(a) educador(a) lança mão de alguns signos (desenhos, gestos, linguagem verbal) e instrumentos (objetos). (SEED, 2009)

Nesse processo de aprender e desenvolver é que se conecta o papel da escola, no sentido de transformar os conceitos cotidianos do(a) educando(a) em conceitos científicos. Os conceitos cotidianos são aqueles de maior familiaridade ao(à) educando(a), mas que este(a) não consegue explicar com profundidade. Para apropriar-se dos conceitos científicos o(a) educando(a) vai realizando generalizações simples e depois mais complexas. Isso exige desenvolvimento da atenção, da memória reflexiva, de abstração, da capacidade de comparar e diferenciar e outras. Quanto mais se apropria dos conceitos científicos, mais consegue explicar os conceitos cotidianos. (VYGOTSKY, 1988)

É a partir dessa compreensão de ser humano que aprende e se desenvolve em relação com o meio, que se formulou a proposta dos Ciclos de Formação Humana, não se reduzindo, portanto, apenas a uma organização temporal, mas estendendo-se a uma preocupação com o processo permanente de desenvolvimento e aprendizagem dos(as) educandos(as), relacionado com a vida e o trabalho, a organização e luta coletiva dos acampamentos.

Desta forma a Escola Itinerante passou a se organizar da seguinte maneira:

\section{Quadro 1 - ORGANIZAÇÃO DOS CICLOS DE FORMAÇÃO HUMANA}




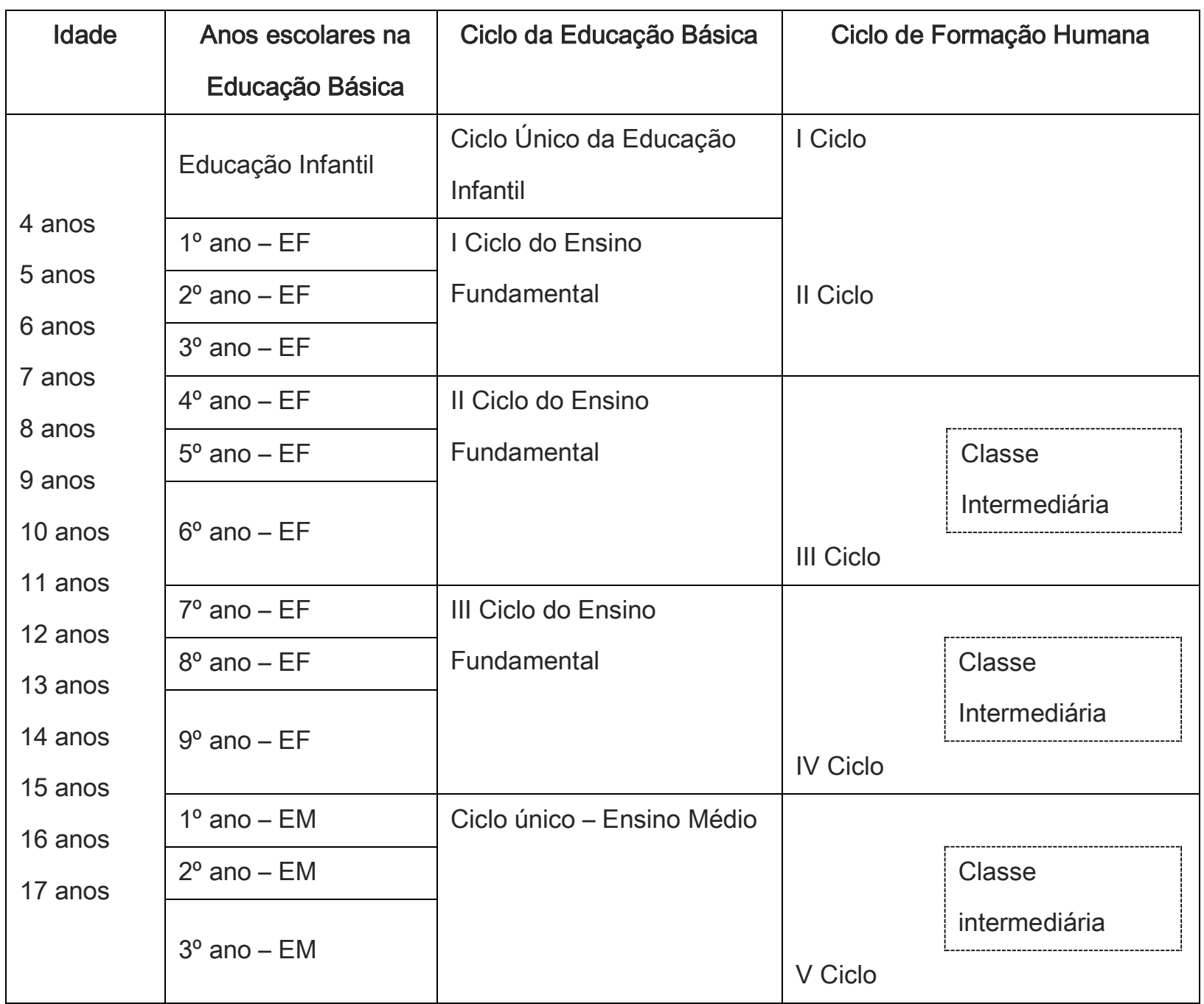

Fonte: SEED (2009, p.42)

Nos Ciclos de Formação Humana a avaliação traz como objetivo central as diversas práticas e espaços formativos na escola, por isso assume o caráter permanente, dialógico, diagnóstico, articulado, com retomadas constantes, relacionando as ações educativas da escola e da comunidade, os conhecimentos trabalhados com o horizonte e a perspectiva dos conhecimentos que precisam ser apropriados pelo coletivo de educandos(as) envolvidos(as) no processo educativo na perspectiva da formação humana. (SEED, 2009)

Neste sentido, foram construídos instrumentos na perspectiva da avaliação emancipatória como: a classe intermediária, os agrupamentos e reagrupamentos, um registro mais qualitativo do que quantitativo da avaliação e o Conselho de Classe participativo, o qual visa uma participação mais efetiva dos(as) educandos(as) e educadores(as) durante todo processo, inclusive no que se refere à avaliação.

\section{CLASSE INTERMEDIÁRIA}

A Classe intermediária foi criada para proporcionar mais aprendizagem nos Ciclos De Formação Humana. Não existe reprovação ao final de cada ciclo, pois entende-se que a reprovação 
não significa que o(a) aluno(a) aprenderá. Dessa forma, a classe intermediária é um espaço para aqueles(as) educandos(as) que não dominam os conceitos e conteúdos necessários para prosseguir na escolaridade. Eles seguem para o ciclo seguinte, porém, em contra turno frequentam paralelamente essa classe.

É chamada Classe Intermediária por se localizar entre um ciclo e outro, e, também, por fazer o intermédio entre aquilo que o educando sabe e o que deveria saber. Outra característica da Classe Intermediária é o trabalho pela área do conhecimento, articulando de fato os conteúdos e sua atualidade. (SEED, 2009)

As Classes Intermediárias não geram matrículas, pois não possuem período fixo, predeterminado. $\mathrm{O}(\mathrm{a})$ educando(a) permanecerá o tempo que for necessário para superar as dificuldades e prosseguir no seu ciclo sem este auxílio. Os(as) educadores(as) trabalham com um número pequeno de educandos(as) e metodologias diferenciadas das habitualmente usadas pelo(a) educador(a) referência da turma. Objetiva, com isto, proporcionar formas diversas de explicar conceitos indispensáveis, para que o educando possa se apropriar do que é necessário para entender os novos conceitos, do novo ciclo que se encontra.

Dessa forma, a classe intermediária é mais um instrumento para romper com a reprovação, que é um dos elementos que contribuem para acentuar a exclusão escolar.

Em sua implementação a classe intermediária passou pelos menos por três limites: o limite no campo legal, da SEED reconhecê-la e viabilizar o contrato de educadores(as) por área de conhecimento (Linguagens, Ciências da Natureza e Ciências Sociais), mesmo aprovadas no Projeto Político-pedagógico; na compreensão do coletivo de educadores(as), pois confundia-se como espaço de recuperação, encaminhando educandos(as) que não estavam com limite entre o final de um ciclo para o outro, mas estudantes que apresentavam dificuldades no processo de aprendizagem encaminha-se para a mesma; na formação dos(as) educadores(as) que atuavam nessas classes, alguns deles, sem ter um preparo com metodologias que pudessem contribuir no desenvolvimento e aprendizagens dos(as) estudantes desde os limites de apropriação por parte dos(as) mesmos(as).

\section{AGRUPAMENTO E REAGRUPAMENTO}

O processo de organização nos Ciclos é realizado através de agrupamentos por idades, agrupamento referência, e, também, os reagrupamentos, que ocorrem entre as diferentes idades tanto dentro de um mesmo quanto entre os diversos Ciclos. Quando se trata de alunos(as) do mesmo Ciclo denomina-se reagrupamento horizontal, quando se trata de sujeitos de diferentes Ciclos, reagrupamento vertical, isso para que os(as) educadores(as) possam trabalhar com as necessidades ${ }^{6}$ e potencialidades ${ }^{7}$ específicas do desenvolvimento de cada grupo. (SEED, 2009)

\footnotetext{
${ }^{6}$ NECESSIDADES, optamos por este conceito em detrimento da ideia de dificuldade. Compreendemos que o sujeito tem maiores ou menores necessidades de apropriação de certo conceito e para isso a escola precisa organizar seu tempo e espaço para desenvolvê-los, superando a linearidade e hegemonia. Portanto, precisamos reagrupar para atender estas necessidades dos sujeitos "aprendentes". As necessidades podem ser na ordem do conhecimento
} 
Os agrupamentos e reagrupamentos representam o esforço em superar a tradicional organização da escola em séries, superar a organização estanque dos(as) educandos(as). Agrupar e reagrupar proporciona ao sujeito aprender e se desenvolver nas relações com os outros, com o contexto e com o objeto a ser conhecido, mas fundamentalmente na qualidade e intensidade vivida pelos sujeitos nessas relações, neste processo o adulto tem o papel de educador, provocador e organizador das relações, as quais devem ser ampliadas e aprofundadas processualmente de sujeito para sujeito e de Ciclo para Ciclo, superando a ideia e a prática da reprovação ou retenção.

As práticas de agrupamento e reagrupamento foram poucas vezes utilizadas, pois a organização em turmas e a responsabilização do(a) educador(a) pela turma direciona a preocupação e intencionalidade educativa para a turma referencia idade/ano. As iniciativas que identificamos na pesquisa de campo, foram realizadas por educadores(as) que tinham aptidões e afinidades em trabalhar em parceria com outros docentes, desenvolvendo o reagrupamento em atividades de leitura, alfabetização, ensino de cálculos matemáticos, como espécie de reforço dentro do próprio ciclo, explicitando o limite dos educadores(as) em pensar estratégias metodológicas conjuntas também pelas potencialidades dos estudantes.

\section{REGISTRO DO PROCESSO DE AVALIAÇÃO}

O registro do desenvolvimento do(a) educando(a), o chamado dossiê ${ }^{8}$, é o instrumento de registro da avaliação contínua, sistemática, processual e interdisciplinar, com encaminhamentos práticos, que precede um acompanhamento do trabalho e do desenvolvimento de cada educando. Nele são arquivados os trabalhos, avaliações realizadas pelo(a) educando(a) nas diversas disciplinas. Estes arquivam e anotam elementos do avanço e dos limites do(a) educando(a) no mesmo documento. O dossiê é ainda espaço para o registro da auto avaliação dos(a) educandos(as) e possui um espaço específico para família fazer suas anotações. Este documento acompanha os(as) educandos(as) em todo ciclo.

Como os resultados da aprendizagem não são expressos em notas, há a construção do parecer descritivo, que é o registro elaborado semestralmente pelos(as) educadores(as), no qual se descreve de forma detalhada o que o(a) estudante aprendeu, mas também seus limites e os seus sucessos. Descreve com fundamento científico desde os conhecimentos trabalhados e os objetivos previstos em cada período, o desenvolvimento de cada educando(a), de forma clara e objetiva e de

como nas relações sociais e elas devem ser superadas com ações de educadores(as) e entre os(as) próprios(as) educandos(as), portanto, estes serão reagrupados pelas necessidades (SEED, 2009, p.31).

7 POTENCIALIDADES. Todo sujeito é sujeito de potencialidades (Vygotsky). São capacidades/potencialidades que o sujeito desenvolveu em sua formação e no contexto social e, que podem ser ainda mais desenvolvidas de acordo com o interesse de cada um e do coletivo, mas fundamentalmente com aquilo que iremos oferecer na escola. São agrupamentos livres ou dirigidos, nas oficinas de arte-educação (música, plástica, cênica...), nas áreas do conhecimento, na organicidade do Movimento e outros, onde os mais experientes ensinam os ainda menos experientes em ofícios, conhecimentos e artes (SEED, 2009, p.31).

${ }^{8} \mathrm{O}$ Dossiê consiste no registro do processo de acompanhamento e avaliação através de anotações sobre suas produções e do relatório de desempenho de cada educando(a). É uma pasta com registro do coletivo de educadores(as) e de acesso aos(às) educandos(as), apresentado à família semestralmente. (SEED, 2009) 
compreensão para a comunidade escolar (educandos(as) e família), para que mediante estas informações descritas, definem encaminhamentos no conselho de classe participativo.

O parecer como instrumento de registro foi sendo aperfeiçoado no decorrer dos anos, mas no cotidiano encontra algumas rejeições explicitadas pelos educadores(as) que fazem registros de forma mecânica, padronizada ou superficial sobre o desenvolvimento e aprendizagem dos educandos(as), estes educadores(as) alegam falta de tempo para se dedicar a este registro questionando este formato de avaliação, reivindicam o retorno das notas, justificando o uso dela como mais eficiente e menos trabalho. De fato, a questão do tempo para os docentes planejarem e avaliarem o processo de desenvolvimento e aprendizagem é uma necessidade, no entanto essas afirmações e práticas de perverter o formato de avaliação, explicitam uma incompreensão de sua lógica e coesão com os ciclos de formação humana.

\section{CONSELHO DE CLASSE PARTICIPATIVO}

Os conselhos de classe participativos na escola têm a intenção de ser um momento em que os sujeitos centrais de toda ação educativa da instituição escolar se encontram para discutir o processo pedagógico, é organizado de forma que todos coloquem as suas opiniões e ideias. Ocorre no final de cada semestre, espaço em que os(as) educandos(as) apresentam avaliação de seus(suas) educadores(as), que fazem a leitura dos pareceres descritivos, sendo que o(a) educando(a) também faz sua auto-avaliação. Além dos(as) educandos(as) e educadores(as), participam os pais. (SEED, 2009)

Os conselhos de classe participativos são considerados espaço-tempo de efetivar a avaliação dialógica, de chamada para o compromisso com o estudo e a formação e não para obter notas. Ele é também um espaço de divisão do poder da instituição escolar, avalia-se nele cada sujeito e cada instância da escola envolvida no processo educativo. Avaliar é parar e olhar o que foi feito e como foi feito, tendo como referência os objetivos que nos propomos a alcançar, e para isso é fundamental o olhar dos diferentes atores envolvidos nesse processo, para que a escola e a sua pedagogia sejam vistas sob diferentes aspectos.

A realização do Conselho de Classe Participativo provocou contradição nas escolas, especialmente, porque os docentes não estavam acostumados a receber a crítica e porque exige a construção de relações horizontalizadas, em 2015, das dez Escolas Itinerantes, duas ainda não realizavam essa forma de conselho, alegando não aceitação do coletivo de educadores(as). As oito escolas que realizavam o faziam parcialmente, indicando haver dificuldades no que se refere, principalmente, à realização da auto avaliação dos(as) educandos(as) e educadores(as), ao registro escrito das discussões feitas e ao compromisso de consolidar, posteriormente, os encaminhamentos combinados para enfrentar as dificuldades apresentadas.

Os Ciclos visam compreender o desenvolvimento humano e provocar o questionamento à escola seriada. Nos estudos de Sapelli (2013) e de Bahniuk (2015), se constata que as escolas, ao realizar esses instrumentos avaliativos, como o parecer descritivo e o conselho de classe participativo, geram frequentemente tensões, de forma mais explícita nos(as) educadores(as) que não têm 
experiência anterior nessas formas de avaliação, sobretudo quando são avaliados(as) pelos(as) educandos(as). Mas esse estranhamento também ocorre entre os pais e os(as) educandos(as), normalmente acostumados a não participar dos momentos de avaliação na escola.

Com o projeto político-pedagógico em Ciclos de Formação Humana, as Escolas Itinerantes, em conjunto com o Colégio Estadual Iraci Salete Strozak, deram mais um passo, avançando para a organização formal dos anos escolares, desde o registro oficial no sistema mas, principalmente, constituindo uma escola que tem como base a formação e desenvolvimento humano pleno, assim sendo fiéis aos objetivos iniciais do Projeto Educativo do MST. Porém, persistem limitações e inquietações mais evidentes em relação ao ensino das bases das ciências e das artes.

\section{OS TEMPOS EDUCATIVOS E A GESTÃO DEMOCRÁTICA}

Outra prática importante nas Escolas Itinerantes foi a organização da escola em tempos educativos, com ampliação de horários de 4 para 5 horas diárias. No quadro 2, apresentamos os tempos educativos existentes e suas intencionalidades:

\section{Quadro 2 - TEMPOS EDUCATIVOS NA ESCOLA ITINERANTE (2003 A 2006)}

\begin{tabular}{|l|l|}
\hline \multicolumn{1}{|c|}{ Tempos Educativos } & \multicolumn{1}{|c|}{ Intencionalidade } \\
\hline Mística & $\begin{array}{l}\text { Tempo diário no início de cada turno em que educandos(as) e } \\
\text { educadores(as) e comunidade se encontram para cantar o hino } \\
\text { Nacional e do MST, vivenciar a mística e dar gritos de ordem, e se } \\
\text { motivar para as atividades educativas da escola. }\end{array}$ \\
\hline Aula & $\begin{array}{l}\text { São quatro horas diárias em que cada turma com seus(suas) } \\
\text { educadores(as) desenvolvem as aulas, as quais são planejadas de } \\
\text { acordo como método e jeito da Escola Itinerante. É levado em conta as } \\
\text { metas de aprendizagem e desenvolvida atividade de leitura, escrita, } \\
\text { pesquisa, cálculos. }\end{array}$ \\
\hline Recreio & $\begin{array}{l}\text { Tempo destinado à alimentação das crianças e, também, ao } \\
\text { desenvolvimento de rodas de brincadeiras conduzidas por } \\
\text { educadores(as). }\end{array}$ \\
\hline
\end{tabular}




\begin{tabular}{|c|c|}
\hline Trabalho & $\begin{array}{l}\text { Visa o aprendizado através do trabalho prático e a compreensão da } \\
\text { organização e de como se desenvolve um processo produtivo, através } \\
\text { de uma área de produção agrícola com espaço de horta orgânica e o } \\
\text { plantio de outras culturas como: batata, mandioca, abóbora, } \\
\text { amendoim... }\end{array}$ \\
\hline Oficina & $\begin{array}{l}\text { Oficinas são tempos e espaços voltados para capacitação, ou seja, } \\
\text { espaço que acontecem as atividades centradas no aprendizado de } \\
\text { habilidades (aprender fazendo), construídas por práticas direta dos(as) } \\
\text { educandos(as), orientada ou acompanhada por educador(a), e } \\
\text { voluntário(a) da comunidade; teatro, flauta, coral, pintura, capoeira, } \\
\text { horta, xadrez, informática, reciclagem de lixo, leitura e "contação" de } \\
\text { histórias, produção de brinquedos com garrafas, tampinhas, etc. }\end{array}$ \\
\hline Educação Física & $\begin{array}{l}\text { Tempo em que semanalmente os(as) educandos(as) praticam esportes, } \\
\text { exercícios físicos, bem como desenvolvem nos jogos relações de } \\
\text { gênero e companheirismo, respeito ao coletivo e desenvolvimento de } \\
\text { aptidões (individuais e coletivas) para os jogos e brincadeiras sadias. }\end{array}$ \\
\hline Tempo Leitura & $\begin{array}{l}\text { O momento orientado pelos(as) educadores(as) para se aprender a ler } \\
\text { e desenvolver o hábito e gosto pela leitura (Literatura Infantil, leitura de } \\
\text { textos...), se informar através de jornais e revistas. Aprender a contar e } \\
\text { ouvir histórias e interpretá-las. Neste momento as crianças ampliam } \\
\text { seus conhecimentos no contato com o fantástico mundo da escrita. }\end{array}$ \\
\hline
\end{tabular}

Fonte: SEED (2003)

Por compreender que a forma também educa, desde o início na Escola Itinerante foi organizada uma gestão escolar alicerçada no exercício da participação e envolvimento. Os(as) educandos(as), os(as) educadores(as) e a comunidade acampada/assentada, foram orientados pelo princípio da democratização da gestão, na gestão administrativa, financeira e pedagógica, e da direção coletiva dos processos pedagógicos.

Para isso, foram organizadas instâncias e espaços coletivos de decisão como: a coordenação da escola, coletivo de educadores(as) e coletivos de educandos(as). Em cada Escola Itinerante, ocorriam de acordo com as condições e necessidades locais. 
Coordenação da escola (direção colegiada): formada pelo(a) coordenador(a) pedagógico, uma dupla de educadores(as) coordenadores(as) do coletivo de educadores(as) da Escola, um representante do Setor de Educação e uma dupla representante dos(as) estudantes. Este coletivo é responsável em coordenar, acompanhar o processo político e pedagógico, articulado com a Escola Base e Setor de Educação do MST e setor de educação do acampamento.

Coletivo de Educadores e Educadoras: espaço de planejamento de ensino, mas também de todo o processo educativo da Escola, os tempos educativos, a auto-organização dos(as) estudantes.

Coletivo de Educandos(as): como centralidade a sala de aula, espaços em que os educandos(as) se organizam nos núcleos de base ou grupo de estudo, formados em torno de 5 a 7 participantes. Cada núcleo elege um menino e uma menina para serem os(as) coordenadores(as). Os núcleos de base têm a função de desenvolver as seguintes tarefas: ajudar no aprendizado em sala de aula (sentar e estudar em grupo), realizar tarefas escolares, fazer a leitura e debate do jornal Sem Terra, contribuir com o embelezamento da escola, a organização e a limpeza da sala de aula, ajuda na distribuição da merenda, preparar a mística, participar ativamente nos momentos cívicos, se reúne semanalmente.

Os coordenadores e coordenadoras dos núcleos de base da turma (Coletivo de Educandos(as)) entre si, elegem o coordenador e a coordenadora da sala de aula e a representação da mesma junto ao conjunto da escola (Coordenação dos Coletivos de Educandos(as) da Escola). Após seis meses, realiza-se uma nova distribuição de tarefa e, consequentemente, uma nova escolha da coordenação dos NB e da coordenação da turma.

A função dessa coordenação é promover a assembleia na turma uma vez por mês, elaborar normas de convivência em sala de aula, avaliar o andamento do processo educativo, propor conteúdos, desenvolver gincanas, promoções, místicas e teatro, desenvolver trabalhos na horta da escola, ajudar-se nas recuperações de conteúdo.

Coordenação dos coletivos de Educandos(as) da Escola formado pelos(as) coordenadores(as) de todas as turmas, entre estes, elegem um menino e uma menina para compor a coordenação da escola, representando os(as) educandos(as). Esta coordenação reúne-se quinzenalmente para avaliar o processo, discutir normas de convivência e ações conjuntas, levantando proposições para coordenação da Escola Itinerante. Há um(a) educador(a) com responsabilidade de acompanhar esta coordenação.

A complexidade desta forma escolar com ciclos de formação humana e gestão democrática horizontal com coletivos, reuniões, funções diversas, oportunizam espaços para os estudantes e docentes exercitarem a participação, o trabalho coletivo e o protagonismo estudantil. $\mathrm{O}$ exercício de implementação desta proposta pedagógica enfrenta desafios constante desde a falta de domínio e compreensão da proposta pedagógica pelos educadores (as) que trocam todo o início de ano em função do contrato temporário, a faltas de subsídios e insumos pedagógico e financeiro para o funcionamento da escola e essencialmente o exercício constante da superação da forma escolar clássica centrada na sala de aula, das relações de poder hierárquicas, e a função da submissão e subordinação da escola capitalista. 


\section{CONSIDERAÇÕES FINAIS}

O processo de construção da proposta pedagógica em Ciclos de Formação Humana nas Escolas Itinerantes do Paraná toma a escola pública real com seus limites e possibilidades e busca cunhar aspectos de uma outra forma escolar, preocupada com a formação e desenvolvimento humano, com autogestão e auto-organização dos(as) estudantes dentro das escolas, porém, essa ação busca também valorizar a socialização do conhecimento científico, em conexão com o trabalho e autoorganização.

A intencionalidade formativa da proposta é proporcionar às crianças, jovens e adultos, a partir da escola, o acesso ao conhecimento das bases da ciência desde uma visão de mundo, desenvolvendo neles as múltiplas dimensões humanas e junto a isso, a compreensão da vida ao seu redor e as ferramentas para mudá-lo radicalmente, para tal, requer também desenvolver habilidades de trabalhar, organizar-se, estudar, lutar, viver coletivamente.

Um dos limites que a escola enfrenta hoje é o esvaziamento do conteúdo escolar, efetivando a máxima de "ensinar tudo a todos", em doses homeopáticas. Há, ainda, outros equívocos, como o de pensar que a extensão do tempo de permanência na escola está diretamente ligada à qualidade de ensino, ou mesmo a uma educação integral. Por isso, a proposta pedagógica avança ao considerar na dimensão formativa dos estudantes o tempo e a fase de desenvolvimento humano, ampliando o tempo escolar para realizar outras atividades na dimensão do trabalho e da auto-organização.

A proposta pedagógica da Escola Itinerante é resultado de longo percurso de luta, estudo e construção coletiva. Como parte desse processo, foram realizados um conjunto de cursos de formação continuada para os(as) educadores(as), que foram imprescindíveis para qualificar os aspectos dos Ciclos na proposta. No processo de sua implantação, uma das principais dificuldades encontradas são as condições de trabalho não adequadas, em função de não ter o tempo necessário para fazer os registros e a sistematização dos pareceres. Também encontram barreiras em superar a concepção tradicional de avaliação.

A nova forma escolar, que se apresenta de forma almejada, partiu de uma base real, concreta. É a síntese possível, construída coletivamente e revela num mesmo movimento o anseio, as contradições oriundas de um sistema educacional tradicional e a luta dos trabalhadores para construir, mediante as brechas do Estado burguês, uma forma escolar que em muito contraria a lógica das relações burguesas.

O desafio vivenciado pelas escolas no período de quinze anos (2003-2018) para a implementação desta proposta é a articulação entre vida, trabalho e auto-organização. Contudo, sabemos que essa experiência enfrenta outras limitações, como rotatividade dos(as) professores(as) que mudam anualmente em função dos contratos temporários, das estruturas e materiais pedagógicos escassos e principalmente das lacunas de formação dos(as) professores (as). Mas os passos dados até o momento são importantes, pois demonstra que é possível uma outra forma de proposta pedagógica e de escola pública que proporcione a socialização das crianças e adolescentes em espaços coletivos, contrariando os modelos de escola que roubam o tempo da aprendizagem, instalam uma competição doentia e ampliam a exclusão dos(as) educandos(as). 


\section{REFERÊNCIAS}

1. BAHNIUK, Caroline. Experiências escolares e estratégia política: da pedagogia socialista à atualidade do MST. Tese (Doutorado) - Curso de Educação, Programa de Pós Graduação em Educação, Universidade Federal de Santa Catarina, Florianópolis, 2015.

2. CAMINI, Isabela. Escola Itinerante: na fronteira de uma nova Escola. São Paulo: Expressão Popular, 2009.

3. CALDART, Roseli Salete. Pedagogia do Movimento Sem Terra. São Paulo: Expressão Popular, 2004

4. FREIRE, Paulo. Pedagogia do Oprimido. 49. Reimp. Rio de Janeiro: Paz e Terra, 2005. 1982.

5. FREITAS, Luiz Carlos. Ciclos, Seriação e Avaliação: confronto de lógicas. São Paulo: Moderna, 2003.

6. KRUG, Andréia. Ciclos de formação: uma proposta político-pedagógica transformadora. Porto Alegre: Mediação, 2002.

7. MARIANO, Alessandro Santos. Ensaios da Escola do Trabalho no contexto das lutas do MST: a proposta curricular dos ciclos de formação humana com complexos de estudo, nas Escolas Itinerantes no Paraná. Dissertação de mestrado apresentada ao Programa de Pós-Graduação da Universidade Estadual do Centro-Oeste do Paraná - UNICENTRO, 2016.

8. MST. Dossiê MST Escola: documentos e estudos 1990-2001. Edição especial. Caderno de Educação, n 13, ITERRA, 2005.

9. OLIVEIRA, Daniela Carla. Práticas de leitura nas Escolas Itinerantes do Paraná. Tese (Doutorado) - Curso de Educação, Programa de Pós Graduação em Educação, Setor de Educação, Universidade Federal do Paraná, Curitiba, 2014.

10. SAPELLI, Marlene Lucia Siebert. Escola do Campo - Espaço de disputa e de contradição: análise da Proposta Pedagógica das Escolas Itinerantes do Paraná e do Colégio Imperatriz Dona Leopoldina. Tese Doutorado, apresentada ao Programa de Pós-Graduação da Universidade Federal de Santa Catarina. 2013.

11. SEED. Projeto Político e Pedagógico da Escola Itinerante. Curitiba, 2003. 
SEED. Projeto Político Pedagógico Colégio Estadual Iraci Salete Strozak. Rio Bonito do Iguaçu, 2009.

13. PISTRAK, Moisey. A Escola-Comuna. São Paulo: Expressão Popular, 2009

14. VYGOTSKY, Lev Semyonovich. Pensamento e linguagem. São Paulo: Martins Fontes, 1988.

\section{Alessandro Santos Mariano}

Doutorando em Educação pela Universidade Estadual de Campinas - UNICAMP e membro do HISTEDBR (Grupo de Estudos e Pesquisas História, Sociedade e Educação no Brasil) Mestre em Educação pela Universidade Estadual do Centro Oeste do Paraná(2016), Especialista em Educação do Campo pela Universidade Estadual do Centro Oeste do Paraná(2015) e em Ensino de Ciências Humanas e Sociais em Escolas do Campo pela Universidade Federal de Santa Catarina(2011), graduado em Pedagogia pela Universidade Estadual do Oeste do Paraná (2008).

\section{Marcos Gehrke}

Graduação em Pedagogia - Licenciatura Plena-Hab pela Universidade Regional do Noroeste do Estado do Rio Grande do Sul (1996); Mestrado em Educação pela Universidade Federal do Paraná (2010) e Doutorado em Educação pela Universidade Federal do Paraná (2014). Atualmente é professor adjunto da Universidade Estadual do Centro-Oeste (UNICENTRO).

\section{Como citar este documento:}

MARIANO, Alessandro Santos; GEHRKE, Marcos. CICLOS, TEMPOS E ESPAÇOS EDUCATIVOS NA PROPOSTA PEDAGÓGICA DAS ESCOLAS ITINERANTES DO MST. Reflexão e Ação, Santa Cruz do Sul, v. 29, n. 1, p. 98-113, jan. 2021. ISSN 1982-9949. Acesso em: doi: 